\title{
Las operaciones de mercado abierto -OMA- instrumento eficaz para el control de la base monetaria: trasegar histórico y pertinencia actual
}

Fecha de recepción: 14 de septiembre de 2010 Fecha de aprobación: 3 de marzo de 2011

\begin{abstract}
Omar Alfonso Ochoa Maldonado
oaochoa@superservicios.gov.co

Superintendencia de Servicios Públicos

Abogado con grado de honor de la Universidad Nacional de Colombia. Especialista en Gestión Pública e Instituciones Administrativas de la Universidad de los Andes; en Derecho Constitucional de la Universidad Nacional de Colombia y en Derecho Privado Económico de la Universidad Nacional de Colombia. Realizó estudios en Filosofía, Pensamiento Político y Económico y es candidato a magíster en Derecho Económico en la Pontificia Universidad Javeriana.
\end{abstract}

\section{Resumen}

Las operaciones de mercado abierto se constituyen en instrumentos eficaces para que el Estado incida en la estabilización de la base monetaria, por cuanto le permiten, a través de la utilización de un mecanismo de mercado sujeto a un proceso que propende por la adecuada formación del precio de los valores negociados, contraer o expandir la citada base, sin limitarse al uso de mecanismos exorbitantes tales como el encaje marginal, los redescuentos o los cupos de liquidez, que revisten el carácter de artificiales y pueden generar externalidades negativas en el entorno macroeconómico. Su utilización marginal actual pone de presente el desaprovechamiento de un instrumento de valía para manejar la política monetaria.

\section{Palabras clave}

Política monetaria, mercado de valores, control monetario, mercado abierto, base monetaria.

\begin{abstract}
The open market operations are effective instruments used by the State to influence in the stabilization of the monetary base because they allow, through the use of a market mechanism subject to a process that aims for the proper formation of prices of securities traded, collapsing or expanding the already mentioned base, without limiting the use of exorbitant mechanisms. Examples of these mechanisms are the marginal statutory reserves, the rediscount quotas, or the liquidity lines, which are considered artificial and can generate negative externalities within the macroeconomic environment. Its current marginal use makes this a wasted instrument of value for managing monetary policy.
\end{abstract}

\section{Keywords}

Monetary Policy, Stock Market, Monetary Control, Open Market, Monetary Base. 
La única medida común que contabiliza la naturaleza de las cosas es el dinero. (...) El dinero es el instrumento que sirve de medida para la cantidad de penas y placeres. A quienes no satisfaga la exactitud de ese instrumento deberian encontrar uno más exacto, o decirle adiós a la politica y a la moral.

Jeremías Bentham

\section{Introducción}

La política de control monetario desarrolla la potestad del Estado de regular el flujo de circulante, apelando para ello a los instrumentos que la legislación monetaria establece para tal efecto. En Colombia, a raíz del pacto político del año 1991, el Banco de la República tiene asignada dentro de sus funciones de estirpe constitucional, la de actuar, por medio de su Junta Directiva, como autoridad monetaria, cambiaria y crediticia. Situación que de suyo le permite al ente emisor poner en movimiento una serie de herramientas tendientes a lograr el equilibrio del mercado de capitales para impulsar el desarrollo sostenido de la economía, en coordinación con la política gubernamental. Sobre el nuevo andamiaje estatal, legatario de la Constitución del año 1991 y relativo a las facultades otrora radicadas en cabeza del Gobierno Nacional y hoy transferidas a la Junta Directiva del Banco de la República, se ha señalado:

Esas capacidades se redujeron de forma drástica en el nuevo arreglo institucional. En materia monetaria (i) se probibió el uso de la
Cuenta Especial de Cambios; (ii) se expidió una reglamentación para la aprobación de créditos al Gobierno por parte del emisor que redujo su acceso a los mismos a una posibilidad teórica; (iii) se estableció que la compra de titulos de deuda pública sólo podía realizarse mediante operaciones de mercado abierto; $y$ (iv) los recursos por señoreaje desaparecieron como fuente de financiamiento del Gobierno (Gandour, 2008, p. 23).

Dentro de esas facultades se destaca la de emitir valores para ser negociados en el mercado de activos financieros, que sirvan como factor catalizador para propender por la estabilidad de la base monetaria. Esa clase de herramientas de control monetario se conocen como Operaciones de Mercado Abierto, OMA, que en los países con economías altamente desarrolladas, tales como EE.UU y Gran Bretaña, constituyen el instrumento monetario más eficaz para la consecución de metas en materia monetaria, controlando el desborde de los medios de pago y manejando la liquidez del mercado, 
tal como se explica en el acápite histórico de este trabajo. Dicha circunstancia constituye un referente de forzosa observancia para las economías emergentes que, como la nuestra, pueden hacer uso de esta valiosa herramienta de control a la base monetaria, como un instrumento catalizador y de estabilización frente a los diferentes ciclos económicos.

Para el óptimo desempeño de esa clase de operaciones se requiere de un conjunto de condiciones materiales que aseguren el éxito del manejo monetario; ese marco de circunstancias está dado por un mercado de capitales desarrollado, que cuente con la suficiente holgura y respaldo de los medios de pago, aunado a una cultura del ahorro y la inversión por parte de los distintos agentes económicos que interactúan en los mercados de activos financieros.

El presente artículo busca acercarse al estudio de la naturaleza, calidades, requerimientos y efectos de las operaciones de mercado abierto, OMA, sobre el conjunto global de la economía. Para esto, abordaremos la materia planteada a la luz de la doctrina económica y jurídica contemporánea, sin descuidar los pronunciamientos jurisprudenciales que permitan tener una visión integral de la utilidad y condiciones de las OMA en nuestro medio, para que cumplan con su objetivo palmario: proyectarse como mecanismos regulatorios de control monetario a disposición del Estado.

Paralelo a las operaciones de mercado abierto, existen otros instrumentos de control monetario con que cuenta la Banca Central como es el caso del encaje, el manejo de la tasa de interés interbancaria, los cupos y los redescuentos, que propenden por el logro de las finalidades enunciadas.
A lo largo del presente documento, examinamos las razones que justifican la validez de mantener y utilizar dichos mecanismos y las ventajas sustanciales que ofrecen las OMA frente a las otras herramientas, motivo por el cual se han convertido en la experiencia reciente de países desarrollados. Estas son el medio más eficaz y moderno dirigido al control de la expansión monetaria, factor que redunda en el control de los índices inflacionarios que entraban al proceso de crecimiento económico e impactan negativamente la consolidación de las estructuras sociales, razón que justifica la existencia de una política de estabilización claramente definida y eficiente respecto del logro de sus metas propuestas.

Siguiendo esos derroteros conceptuales, la hoja de ruta propuesta abarca la definición conceptual, características y alcance de las OMA, su relación con el endeudamiento público y su carácter regulatorio del mercado monetario. Posteriormente se examinará su origen y desarrollo histórico, haciendo énfasis en el caso colombiano, para desde allí describir los diferentes instrumentos de control monetario que la Banca Central tiene a su disposición y cotejarlos con las OMA, para lo cual se efectúa una sinopsis en relación con las funciones y efectos de este tipo de operaciones sobre los diferentes agregados monetarios y las condiciones macroeconómicas idóneas para su desarrollo.

Por otro lado, es pertinente también adentrarse en el estudio del instrumento a luz del marco normativo y su tratamiento de orden jurisprudencial, así como el mecanismo de colocación vigente utilizado por el emisor, para finalmente arribar fruto del acumulado conceptual descrito, a unas conclusiones a título 
de aporte y proyección crítica del instrumento bajo estudio.

\section{Definición y alcance}

Las operaciones de mercado abierto son un instrumento de política monetaria que consisten en la oferta o demanda de valores ${ }^{1}$ por parte del Banco Central, con el objeto de incidir en la regulación (expansión o contracción) de la base monetaria. Lo anterior se traduce en la compra o venta de activos mobiliarios, generalmente títulos de deuda pública, con la finalidad específica de ejercer control sobre los medios de pago.

La motivación principal por parte del emisor responsable de la política monetaria para la realización de este tipo de operaciones financieras, es la producción de variaciones en la base monetaria, de tal suerte que se causa una externalidad positiva mediante la compra de tales títulos aumentando los medios de pago, toda vez que se le inyectan recursos al mercado. Poe el contrario, con su venta se efectúan ejercicios de contracción, especialmente en periodos de abundancia en la base monetaria, congelando los recursos captados por esa modalidad en el emisor, para contrarrestar el exceso de circulante, hecho que redunda en desequilibrios macroeconómicos de gran magnitud.

Sintéticamente el Banco Central gestiona la política monetaria a través de la

\footnotetext{
El concepto de valor lo encontramos definido en el artículo 2 de la ley 964 de 2005, el cual establece: Para efectos de la presente ley será valor todo derecho de naturaleza negociable que haga parte de una emisión, cuando tenga por objeto o efecto la captación de recursos del público (...).
}

realización de OMA, como lo señala la teoría: En una operación de mercado abierto, el Banco Central compra bonos a cambio de dinero, aumentando asi la cantidad de dinero, o vende bonos a cambio de dinero pagado por los compradores de los bonos, reduciendo asi la cantidad de dinero (Dornbusch, Fischer, Startz, 2004, p. 289).

La Constitución Política de 1991 ha querido diferir expresamente al Banco de la República, el mandato de velar por el mantenimiento del poder adquisitivo de la moneda (art. 373, C.P.), lo cual se traduce en el control de la inflación, cuyo resultado más patente es el alza sostenida en el nivel de precios del mercado, generando efectos en materia de la capacidad de compra que impactan negativamente sobre todo a los sectores más vulnerables que padecen con mayor rigor las consecuencias del alza sostenida en el nivel de precios. Para contrarrestar eficientemente esa situación, el Estado cuenta entre otras herramientas, con las OMA como mecanismo de estabilización de la base monetaria.

Las operaciones de contracción o expansión de la base monetaria constituyen un mecanismo de intervención del emisor, en primer lugar para controlar incrementos en el nivel general de precios y, en el segundo, supuesto para brindar liquidez a los agentes e incentivar la contratación de créditos incidiendo directamente en la oferta agregada.

La base monetaria a la cual nos referimos, es la suma de todos los pasivos monetarios del Banco de la República y la tesorería con los diferentes agentes de la economía, excluyendo la deuda de los bancos comerciales con el público, pero incluyendo a su vez las deudas del Banco de la República con el sistema financiero en su conjunto. 
Ahora bien, para el adecuado funcionamiento de esta estrategia, debe contarse con un mercado de valores profundo que haga viable la utilización del instrumento descrito como mecanismo decisivo para estabilizar la base monetaria.

En ese orden, como características esenciales de esta clase de instrumentos para el control monetario, tenemos las siguientes:

I. Se basan en decisiones voluntarias de los agentes económicos

II. Se realizan a través de títulos representativos de deuda pública

III. Poseen una gran flexibilidad. La autoridad monetaria puede actuar en forma inmediata sobre la liquidez de la economía mediante el uso de las operaciones de mercado abierto (Botero, 1987, p. 5).

El estudio de su composición y comportamiento lo abocamos a la luz del derecho público económico, concepción jurídica que despierta un inusitado interés por el perfil de su estructura, aún en ciernes:

En verdad tales regulaciones trascienden el dominio de las ramas juridicas tradicionales y por eso hay doctrinantes que abogan por la estructuración de una parcela independiente, de naturaleza mixta por cuanto participa a la vez del derecho privado y del derecho público, comprensiva de la normatividad que el Estado promulga en desarrollo de politicas concernientes al ahorro, las inversiones, el crédito, el mercado de capitales, los estimulos a la producción de bienes y a la prestación masiva de servicios, al comercio interno y al intercambio internacional, asi como las directrices para que la función social de la empresa y de la propiedad tengan efectividad (Narváez, 1993, p. 61).

Lejos de la simple exégesis, nos adentramos a escudriñar los escarpados senderos del dinamismo de los sistemas económicos para auscultar en los instrumentos de control monetario, la trascendencia real de las OMA como factor preponderante de control, respecto al comportamiento de la base monetaria.

A continuación presentamos las relaciones conceptuales que en la praxis genera la utilización del instrumento, frente al endeudamiento público, toda vez que se realizan por regla general con títulos de deuda pública.

\subsection{MA y deuda pública}

Es fundamental diferenciar conceptualmente que frente a la utilización de las OMA, a pesar de realizarse con títulos de deuda pública, su objetivo no se enfoca en lograr el saneamiento del agudo déficit presupuestal del Gobierno Nacional. Por el contrario, sus objetivos hacen relación a la estabilización y el equilibrio de la base monetaria circulante, absorbiendo excesos de liquidez que causen traumatismos al sistema en situaciones de escasez y posibilitar el acceso a medios de pago mediante la recompra de los títulos inicialmente emitidos, en efecto:

La filosofía de las operaciones de mercado abierto nada tiene que ver con la financiación del presupuesto gubernamental, ni con la sustentación de la deuda pública y que el Banco Central persigue exclusivamente aumentar o contraer la liquidez del sistema bancario $y$, por ende, la capacidad crediticia del mismo, o 
sea, la creación y esterilización del dinero (Pieschacón, 1976, p. 49).

Siguiendo esos derroteros de interpretación, es ilustrativo y pertinente referirse a la importancia de utilizar este mecanismo de manera independiente al sostenimiento del déficit fiscal para no generar traumatismos y desajustes monetarios con nocivas consecuencias postreras que se derivarían para las variables macroeconómicas, en efecto:

Con respecto a la participación del Banco Central en la financiación del déficit presupuestal, el punto principal no es si el Gobierno debe o no prestar del Banco Central, sino si los fondos deben obtenerse del sistema bancario o del público no bancario. Cuando la deuda se vende al público, es adquirida con saldos de deuda ya existente; cuando es adquirida por los bancos, es en realidad adquirida con moneda nueva creada para tal propósito. En el último caso, los medios de pago en las manos del público se aumentan; mientras en el primer caso el aumento de los activos del público se realiza en la forma de deuda. Puesto que la moneda es más líquida que la deuda, recurrir al crédito de los bancos es el procedimiento más inflacionista (Restrepo, 1996, p. 14).

Los anteriores razonamientos se traducen en el riesgo de financiar el déficit fiscal con emisión de dinero, situación que impacta negativamente el poder adquisitivo de la moneda por cuanto en esas circunstancias hay más dinero circulante para adquirir los mismos bienes, toda vez que con la simple emisión no se genera ninguna inversión en bienes de capital o en obras de infraestructura, lo cual presiona la subida sostenida en el nivel de los precios, gestándose fenómenos inflacionarios que se erigen en el óbice principal al desarrollo global de la economía, así como una talanquera frente a su crecimiento sostenido.

En ese sentido, cobra relevancia la necesaria coordinación entre la política fiscal y la monetaria, a pesar del margen de autonomía con el que cuentan las autoridades responsables de cada frente de acción, en especial la pertinencia del principio de la coherencia macroeconómica orientador en materia presupuestal (art. 20 de la Norma Orgánica de Presupuesto compilada en el Decreto 111 de 1996) frente a las atribuciones exclusivas del Banco de la República. Sobre ese particular la doctrina ha señalado:

En los últimos tiempos la relación entre politica fiscal y politica monetaria ha sido objeto de apasionadas discusiones entre los economistas (Kosh, 1976, p. 167). Mientras que un sector seguidor de la doctrina de Keynes, otorga prioridad al fomento de una política presupuestaria anticiclica, otro sector que se inspira en la escuela de Friedmann (1969) considera prioritario en ejercicio de una politica monetaria (Reich, 1985, p. 119).

Como se aprecia, existe una inveterada simbiosis entre el manejo fiscal y la política monetaria, circunstancia que se hace patente en la relación planteada entre el gasto público y la celebración de operaciones de mercado abierto que tienen como subyacente títulos de 
deuda pública gubernamental, tal como en efecto ocurre en el caso colombiano.

Como lo señala la teoría económica: "La política monetaria estimula la economía elevando la inversión y las exportaciones netas" (Stiglitz, 1998, p. 367). De lo anterior se colige que cuando los estímulos a la economía provienen de la política monetaria, el efecto en el crecimiento es más benéfico que cuando dichos incentivos se efectúan con cargo a la política fiscal, salvo cuando el gasto público se enfoca en la inversión social o de bienes de capital.

A continuación se realizará la descripción de las funciones de estirpe regulatorio que cumplen las OMA en el contexto del mercado monetario.

\subsection{Funciones reguladoras}

Adicional a su función reguladora del circulante, las OMA desempeñan otros roles en relación con diversos factores de la economía: en cuanto a las tasas de interés en el corto y el largo plazo, pues reducen o amplían la presión sobre la liquidez en el sistema financiero, y en cuanto al multiplicador monetario, por el incremento en la oferta de fondos en el resto de la economía e incluso sobre agregados de dinero más amplios.

Las decisiones sobre política monetaria tienen una incidencia directa sobre las tasas de interés, la demanda y la política cambiaria, todo lo cual termina reflejándose inexorablemente en el nivel global de precios. Bajo ese entendido, las OMA constituyen un factor regulador que actúa desde el seno del mismo mercado de dinero y en consonancia con la dinámica del mismo, sin crear restricciones impositivas en el flujo de recursos entre agregados.

Las anteriores incidencias se logran sin crear distorsiones artificiales por tratarse de un instrumento basado fundamentalmente en la fuerza del mercado. Por esta razón, reviste el carácter de una herramienta flexible y eficaz en el manejo de la política monetaria por sobre los otros mecanismos como el encaje y los redescuentos, que son factores rígidos e impuestos unilateralmente y que en consecuencia no consultan el factor volitivo, elemento que es una constante en el manejo de las OMA por cuanto revisten el carácter de contratos financieros de colocación o compra de valores en el seno del mercado secundario.

\section{Reseña histórica}

La inveterada disputa conceptual entre las doctrinas Currency Theory y Banking Theory, sirvió de caldo de cultivo para las condiciones necesarias para la gestación de las operaciones de mercado abierto como instrumento de control monetario en Inglaterra. La controversia se centraba en el papel y funciones que debería asumir el Banco Central, siendo la primera escuela partidaria de controlar el circulante como un todo sistémico, mientras que los segundos propendían por la regulación del crédito en sí mediante la financiación de actividades productivas.

En ese contexto, fue precisamente Inglaterra el país pionero en el establecimiento de las OMA como dispositivo para la regulación de la cantidad de dinero en circulación en el año de $1696^{2}$,

Sobre el particular es pertinente la consulta del siguiente enlace web: http://www. britishmuseum.org/explore/highlights/ highlight_objects/cm/e/exchequer_bill_ for_\%C2\%A3100.aaaaaspx. 
mediante la expedición de los exchequer bill. Estos eran, en principio, mecanismos de pago que reemplazaban el efectivo de una forma más elástica, tomando partido a favor de la doctrina expuesta por los partidarios de la Banking Theory, que propugnaba por la liberalización de los medios de pago como mecanismo para irrigar liquidez a las diferentes actividades productivas que impulsaran el crecimiento económico, apalancado desde sectores superavitarios a sectores deficitarios, que requerían del crédito para la potenciación de los renglones productivos.

El avance de las operaciones de mercado llegó a un hito histórico en el año de 1913 en los Estados Unidos, época en la cual se expidió la Ley de Reserva Federal, normatividad que autorizó a los bancos para la realización de compras y ventas de títulos a efectos de incidir en el medio monetario circulante. Lo anterior en respuesta al debilitamiento que había experimentado la banca norteamericana frente a la europea en esa coyuntura histórica en particular. En Estados Unidos se ha alcanzado el cénit del orbe a nivel del desarrollo de las OMA, gracias al impulso y utilización histórica del instrumento dentro de unas condiciones económicas favorables para su eficacia.

La doctrina da cuenta de la aparición tardía de estas operaciones en la banca europea salvo el caso ya expuesto de Inglaterra como antecedente, en razón del apego férreo que se profesaba a los principios ortodoxos de la emisión. Aunque existieron con anterioridad visos de materialización en los mercados financieros, fue sólo con el advenimiento de la segunda posguerra que se consolidaron como factores decisivos para el control monetario:
En muchos casos este tipo de operaciones habia existido legalmente desde la década de los treinta o los años siguientes a la Segunda Guerra Mundial, en que se revisaron las constituciones de los bancos centrales y se redactaron otras nuevas. Sin embargo, por una u otra razón, a causa de los mercados débiles, procesos de financiamiento y otros factores técnicos, las operaciones de mercado abierto se utilizaron principalmente en relación con la administración de la deuda pública y sólo en ocasiones con propósitos monetarios (Pinzón, 1983, p. 27).

El acuerdo suscrito entre la Tesorería y la Reserva Federal en los Estados Unidos, marcó el derrotero para el cambio de procedimientos en tratándose de la política monetaria, dejando desueto el viejo sistema consistente en sostener los precios con bonos gubernamentales. Se dio lugar así, a otras alternativas tales como la ampliación de los mercados de dinero en el corto plazo, con tasas de intereses flexibles, negociando valores con diferentes tasas de retorno. Adicionalmente los bancos centrales cobraban más autonomía en la emisión de documentos para el control de la política monetaria de manera libre y sin sujeción a la coyuntura o prioridades gubernamentales, lo cual robustecía la utilización de instrumentos como las OMA para el control del circulante.

\subsection{El caso colombiano}

En el país el tema monetario fue objeto de preocupación de diversas administraciones. Cabe resaltar el desgreño fiscal que implicó el modelo liberal prohijado por el Olimpo Radical al amparo de sus 
tendencias federales y autónomas en las regiones y la posterior introducción de instituciones regulatorias de la moneda, hasta la reivindicación del monopolio de su emisión por conducto de la expedición del Acto Legislativo 01 de 1905 durante el quinquenio del General Rafael Reyes.

Sobre ese particular y el legado de ese período histórico se ha reconocido un importante papel de la Regeneración en disciplinar el manejo monetario en el país, en efecto:

Le correspondió a los gobiernos de la Regeneración orientar una etapa de inmensos avances conceptuales en el proceso de modernización de nuestras instituciones monetarias. Quizás ningún otro periodo de nuestra historia económica registre un despliegue tan opulento de inteligencia como en que exhibieron los hombres de la Regeneración - presididos por Rafael Núñez y Miguel Antonio Caro-para explicar a sus contemporáneos y para aclimatar en el pais conceptos que aunque hoy nos parecen elementales y obvios, en su momento representaron una verdadera revolución conceptual en el campo monetario (Restrepo, 2005, p. 54).

Las postreras décadas fueron testigos de una serie de innovaciones en materia de la modernización de nuestro pueril sistema monetario, especialmente a raíz de las reformas impulsadas a instancias de la misión Kemmerer de 1923 y especialmente desde la creación del Banco Central con funciones en materia de emisión y control monetario.

En ese orden de ideas, desde la $M i-$ sión Currie en 1950 se empezó a plantear la necesidad de reforzar las funciones del Banco Central otorgándole expresa autorización para realizar operaciones de mercado abierto y, de esa forma, lograr un manejo adecuado de la política económica del país. Nuestro ordenamiento positivo siguiendo las directrices planteadas, consagró en el Decreto 2206 de 1963 , contentivo a la sazón de las funciones del Banco de la República, la autorización expresa a este ente para emitir, vender, comprar y autorizar títulos de crédito en moneda nacional o extranjera en las condiciones que para tal efecto fueran determinadas por la entonces Junta Monetaria. Así mismo, permitió la inversión en el mercado de documentos para lograr control sobre la base monetaria, dando vía libre, con sustento legal, a la compra y venta por cuenta propia, de obligaciones emitidas o garantizadas por el Gobierno Nacional.

Durante ese período se destaca también el manejo monetario expansivo por parte del Gobierno Nacional por conducto del emisor consecuente con la política de incentivos a las exportaciones, en efecto:

Otro cambio importante en el régimen monetario colombiano fue la creación de la Junta Monetaria en 1963, constituida por los ministros del Gasto y Hacienda, más dos asesores de buen nivel técnico, que dio lugar al ejercicio de la política monetaria por parte del Gobierno, produciendo un relajamiento de las reglas de emisión y, con ello, un aumento permanente de los niveles de inflación (Kalmanovitz, 2010, p. 170).

A pesar de su consagración en la norma comentada, esta clase de operaciones 
empezaron a cobrar importancia solamente hasta principios de la década de los años setenta, precisamente en 1974 período en el cual la Junta Monetaria autorizó la emisión de títulos de participación. Durante aquél periodo se señalaba en relación con la inflación y el control de la base monetaria que:

En Colombia el control de los medios de pago se ha buscado a través del gasto público así como de diversas medidas de control monetario. En ese contexto, la explicación del crecimiento de la inflación en el periodo 1970-1974 puede residir en el crecimiento del gasto público experimentado en esos años. Posteriormente, el boom cafetero de 1976, con el consiguiente aumento de las reservas internacionales, debió contribuir a un repunte de la inflación. El proceso de estabilización de estos años se centró en el control del aumento en los medios de pago (Garay, 1996, p 2).

Como se aprecia, a pesar de que históricamente el control a la expansión monetaria se realizó utilizando el encaje marginal, las tozudas realidades de una inflación galopante hacían necesario robustecer con mayor ahínco el mecanismo de las OMA como instrumentos para lograr tal cometido, sin distorsionar las realidades inherentes al mercado ni desestimular las actividades productivas dependientes del crédito.

En un comienzo, las OMA se debieron reservar para compensar emisiones estacionales y otras de carácter transitorio del Banco de la República. Así mismo, se enfocaron en la solución de problemas deficitarios de la tesorería.
Durante la primera década de su utilización, el saldo de OMA alcanzó un promedio de participación dentro de la base monetaria de 1,4\% (Pinzón, et. al, 1983), lo cual constituía un monto poco significativo en su momento. A pesar de esto, el instrumento se empezaba a perfilar como la alternativa frente a las rigideces del encaje, del depósito de importaciones, los cupos y las tasas de redescuento, elementos carentes de la flexibilidad que poseen las OMA para ser negociadas de acuerdo con las leyes de la oferta y la demanda, brindando un manejo más ágil y flexible para el control de la oferta monetaria.

A mediados de los años ochenta las OMA se utilizaron de una forma más recurrente, jugando un trascendental papel en el manejo de los recursos provenientes de la bonanza cafetera entre 1985 y 1986, neutralizando la entrada masiva de capitales mediante las operaciones en estudio. Idéntico mecanismo se usó para los fines previstos en relación con los excedentes de Ecopetrol. Como corolario de lo anterior, el saldo de las OMA a finales de 1986 se constituía en el 29\% de la base monetaria, lo que representa un inusitado repunte en su afianzamiento como instrumento contraccionista y de estabilización.

A principios de la década de los noventa y en virtud de la acumulación de reservas internacionales, se adoptaron medidas contundentes para esterilizar el exceso monetario. Paralelamente al encaje marginal del $100 \%$, los certificados de cambio y el incremento en las tasas de interés, se aumentaron la captación de recursos por las operaciones de mercado abierto, llevando a participar de un 58,7\% del total de la base monetaria. En los años subsiguientes, la tendencia se ha mantenido, 
oscilando entre un $33,5 \%$ y un $38,7 \%$ como saldo de OMA.

En principio, las operaciones de mercado abierto se realizaban con títulos de participación por regla general. Esta clase de títulos se subdividían en títulos de participación Clase A y B y títulos canjeables por certificados de cambio emitidos por el Banco de la República. Los títulos Clase A se colocan al 100\% de su valor y devengan una tasa de interés previamente determinada por el Banco Central. Por su parte, los títulos Clase B se colocan con descuento y su rendimiento está determinado por la diferencia entre su valor nominal y el valor de compra.

Ambas clases de títulos eran redimidos a su vencimiento por su valor nominal. Se establecía adicionalmente que una vez vencido el título, el mismo no sería prorrogado ni renovado automáticamente, tampoco habría lugar al pago de rendimientos con posterioridad a su vencimiento.

Cabe resaltar que a partir del mes de agosto de 1996, los títulos de participación se colocaron únicamente mediante el mecanismo de subastas, realizadas a través de los Agentes Colocadores de OMA previamente aceptados por el Banco central para tal fin, según lo dispuesto en la Circular Reglamentaria DFV-87 de 1996 expedida por el Banco de la República.

En cuanto a los títulos canjeables por certificados de cambio, cabe indicar que estaban denominados en dólares estadounidenses y eran emitidos por el Banco de la República con cargo a las reservas internacionales del país, con el fin de ser adquiridos como inversión por las entidades públicas, el Fondo Nacional de Cafeteros y las instituciones financieras públicas del sector eléctrico.
Los títulos de participación Clase A se crearon para tener como destinatario de la inversión al sector público en su conjunto y ocasionalmente para captar excedentes de liquidez en el sistema bancario.

Los títulos en comento servían para captar el ahorro del sector privado y su colocación se realizaba por el sistema de subasta pública o mediante agentes colocadores debidamente autorizados para tal efecto. Durante un período considerable de tiempo, el Banco colocaba esta clase de títulos por venta en ventanilla; este sistema se usaba aún en ciudades intermedias en pequeñas proporciones hasta el año 1996, tal como se indicó antes. Para el control monetario de largo plazo, el instrumento utilizado son las OMA definitivas, las cuales, en general, se realizan a plazos mayores de 60 días.

Sobre la utilización y funcionalidad de las OMA en ese período en particular se destaca:

En el caso colombiano, se destaca, en lo referente a la colocación de titulos en el mercado con fines de regulación monetaria, en empleo de los "Títulos de Participación" emitidos por el Banco de la República. También se muestra en uso del "certificado de cambio", modalidad muy particular de control monetario, diseñada para enfrentar las presiones de expansión de dinero originadas en los cuantiosos ingresos de divisas que recibió el país en ciertos periodos. Este mecanismo se eliminó a partir de 1994, como consecuencia de las reformas en materia cambiaria y de comercio exterior adaptadas a comienzos de la década de los noventa (Banco de la República, 2002, p. 161). 
Especial referencia merece la expedición de la ley 51 de 1990 la cual crea los actuales Títulos de Tesorería TES, tanto los de la Clase A como los de la Clase B. Los primeros, destinados a saldar la deuda histórica acumulada por el Gobierno Nacional con el Banco de la República y los segundos, reemplazarían los antiguos Títulos de Ahorro Nacional TAN cuya finalidad es financiar gasto público u operaciones temporales de tesorería según el plazo de maduración del título. Sobre ese tipo de emisiones se indica:

Con los titulos de la clase $A$ se busca sustituir los papeles del Banco de la República; con los cuales se están haciendo las operaciones de mercado abierto y los documentos que respaldan la deuda consolidada de la Nación con el Banco de la República. Estos son los títulos de tesorería que pueden, tienen o pueden tener propósitos monetarios, o sea, estarían vinculados a las nuevas modalidades de mercado abierto (Restrepo, 2005, p. 386).

El siguiente esquema nos muestra el comportamiento de las operaciones de expansión y contracción monetarias realizadas por el Banco de la República durante el año 2002, evidenciando el cupo asignado y el porcentaje utilizado a través de las subastas holandesas ${ }^{3}$ a tra-

La Subasta Holandesa es un tipo de subasta en la que el subastador comienza fijando un alto precio, que es rebajado hasta que algún participante esta dispuesto a aceptar el precio del subastador, o hasta que se llega al precio de reserva, que es el precio mínimo aceptado para esa venta. El participante ganador paga el último precio anunciado. Este vés de las cuales se efectúan este tipo de transacciones.

Cabe resaltar que en la actualidad el Banco de la República no expide títulos propios y las operaciones de control monetario las realiza básicamente con títulos de deuda pública emitidos por el Gobierno Nacional, tales como los TES Clase B. Lo anterior, en virtud a lo establecido en su momento en el artículo 53 de la ley 31 de 1992 el cual estableció que a partir de 1999, las operaciones de mercado abierto en moneda legal se realizarían exclusivamente con títulos de deuda pública, al limitar la posibilidad de que el Banco Central emitiera títulos propios para esos propósitos. Restricción motivada claramente en propender por la profundización del mercado de deuda pública a través de la colocación de Títulos de Tesorería, TES, tanto en el mercado primario como en el secundario.

No obstante lo anterior, cabe resaltar que el citado precepto fue recientemente derogado por la ley 1328 de 2009, respecto del cual en también reciente oportunidad, la Corte Constitucional señaló:

Habiéndose pronunciado en varias oportunidades esta corporación sobre la autonomía de la Banca Central y las funciones que el Banco de la República debe ejercer para mantener la capacidad adquisitiva de la moneda, siendo su Junta Directiva la autoridad monetaria, cambiaria y crediticia de Colombia (arts. 371, 372, 373, 113, 150-22 Const.), advierte la

\footnotetext{
tipo de subasta es conveniente cuando es importante subastar los bienes rápidamente, y una venta nunca requiere más de una puja, que es aumentar el precio puesto a algo que se subasta.
} 
Corte que en este caso no puede emitir pronunciamiento alguno, pues en el curso del proceso fue expedida la ley 1328 de 2009 (15 de julio), "Por la cual se dictan normas en materia financiera, de seguros, de mercado de valores y otras disposiciones", cuyo articulo 101 derogó expresamente el parágrafo del artículo 53 de la ley 31 de 1992, norma acusada. (Corte Constitucional, Sala Plena, Sentencia C-680 de 2009, Mag. Ponente: Dr. Nilson Pinilla).

Así las cosas, en la actualidad surge nuevamente la posibilidad de efectuar este tipo de operaciones con cargo a títulos que ofrezca el mismo emisor, situación que es más consecuente con la finalidad de las OMA y que sirve para deslindarlas del manejo de la deuda pública, tal como se indicó en el acápite respectivo.

Frente a la historia del manejo de instrumentos monetarios cabe resaltar que los fenómenos vividos a finales de la década de los noventa, consistentes en la falta de liquidez en el mercado, propugnaban por la compra de títulos por parte del emisor con el fin de expandir la base e inyectar recursos monetarios al mercado, abaratar el costo del dinero, controlar las elevadas tasas de interés y, de esa forma, buscar alternativas frente a situación de recesión que en su momento justificó la declaratoria de emergencia económica a través del Decreto 2331 de $1998^{4}$.

La actividad económica general se frenó de tal modo que en 1998 el crecimiento económico fue de apenas el 0.6\%, cifra engañosa por cuanto algunos sectores crecieron muy por encima del promedio, particularmente los asociados a minerales y energía, pero
A partir de octubre de 2002, el Banco de la República optó por la estrategia de fijar una "inflación objetivo" como indicador de referencia que orientara su accionar, con lo cual el mecanismo de operación de la política monetaria dejó de concentrarse en fijar la trayectoria de los agregados monetarios en unos -estrechos corredores-, para orientarse más bien hacia la fijación de las tasas de interés de referencia, nuevo instrumento primario de la politica (Zuluaga, 2004, p. 7).

Cabe resaltar que las citadas operaciones se realizan en la actualidad básicamente a través de la realización de operaciones de reporto pasivas y activas, cuyo régimen legal se encuentra contenido en el Decreto 4432 de 2006, actualmente recogido en el Decreto 2555 de 2010, en donde se consagran las características y efectos jurídicos de la celebración de este tipo de operaciones en el mercado y que actualmente tienen una duración máxima de 365 días.

La funcionalidad de las citadas operaciones consiste en la celebración de éstas a través de la realización de subastas diarias en las cuales se adjudica el cupo establecido entre los intermediarios financieros que ofrezcan mejores tasas. Cuando no se fija de antemano un límite en la cantidad de dinero que quiere ofrecer el Banco de la República, la operación se realiza a una tasa previamente definida por el emisor (Corfivalle, 2006).

otros se contrajeron significativamente. Tal fue el caso del sector financiero que cayó en un $6 \%$ en éste, el primer año de la crisis. Vendrían aún tiempos peores. La tasa de desempleo subiría a casi un tercio entre 1997 y 1998, ubicándose al final del año en cerca del 16\%. Las reservas internacionales caerían a los niveles de 1990 (Restrepo y Núñez, 2009). 
Una vez descrito el mecanismo, es de recibo a renglón seguido efectuar un paralelo con los demás instrumentos de control monetario, en aras de determinar su grado de eficacia en el mercado monetario.

\section{Instrumentos de política monetaria}

A continuación se esbozarán los elementos que configuran los principales instrumentos de control monetario necesarios para determinar en ese contexto la utilidad o pertinencia de utilización de las OMA.

\subsection{Encaje}

Se trata del instrumento tradicional y común utilizado para influir en la oferta monetaria, mediante la reserva bancaria, regulando así la expansión secundaria de dinero. El telos de la figura en estudio se concentra en metas de control monetario al largo plazo. Sobra señalar que el encaje es de carácter obligatorio e impositivo, recayendo sobre los intermediarios financieros el peso de la restricción monetaria, haciendo crecer el margen de intermediación.

Se evita de esa forma la monetización de altos volúmenes de reservas internacionales. Como efecto práctico se evidenció el hecho de que las instituciones estimularan la composición de sus depósitos, induciendo a sus clientes a transferir sus recursos hacia CDTs y cuentas de ahorro afectadas con un menor encaje. La consecuencia de la excesiva utilización de un sistema tan rígido, es la desaceleración del dinamismo económico que hace proclive al esquema a una crisis en su desarrollo por la inelasticidad del instrumento. Sobre el particular se advierte:

La experiencia del manejo de la politica monetaria en los últimos años muestra cómo, ni siquiera encajes marginales del $100 \%$ son sufcientes para controlar el crecimiento de los medios de pago, y que hay necesidad de recurrir a operaciones de mercado abierto como la realizada indirectamente con los certificados de cambio. Se debe tener en mente para el futuro de la politica monetaria que el encaje debe ser lo más estable posible y que se deben utilizar las operaciones de mercado abierto para cubrir las fluctuaciones de corto plazo en el volumen de las reservas de los bancos comerciales (Ramírez H., 1985, p. 101).

De lo anterior se colige que los dos mecanismos antes que ser excluyentes, son complementarios en la medida que la disminución del encaje puede ser compensada con el aumento en la colocación de títulos, con el fin de minimizar el efecto inicial de la expansión de las reservas bancarias liberadas.

La tendencia a favorecer las OMA se patentiza en su versatilidad:

Desde el punto de vista de la flexibilidad en la aplicación de los instrumentos, las OMA se pueden adecuar a las circunstancias monetarias del momento más rápidamente que los encajes. En efecto, las condiciones (tasa de interés, etc.) de los titulos se pueden modificar cuando el momento lo requiera, y asi controlar cambios indeseados en los medios de circulación (Botero et. al., p. 200). 
La utilización de un encaje excesivo, atenta contra el rendimiento en las operaciones de cuenta corriente bancarias, eleva las tasas de intermediación y dificulta la consecución de crédito y el crecimiento económico, incentivando la búsqueda de recursos en el mercado extrabancario.

\subsection{Los certificados de cambio}

Se usaban para diferir en el tiempo la monetización de las reservas internacionales mediante el establecimiento obligatorio de la adquisición de títulos de cambio, los cuales con un interés determinado, demoraban los efectos de un incremento monetario producido por la conversión de divisas. En la actual coyuntura caracterizada por la apreciación del peso frente al dólar, se propugna por su utilización o la de un sucedáneo que evite la monetización de ingresos y la proliferación de divisas en el mercado cambiario.

\subsection{Cupos de liquidez}

La utilización de estos mecanismos es buscar solucionar coyunturalmente problemas de liquidez de manera individual, sin contribuir de manera decisiva a solucionar los problemas estructurales del mercado.

\subsection{Repos}

Las operaciones repos se erigen por antonomasia en el instrumento adecuado para el manejo de las distorsiones monetarias a corto plazo; su funcionalidad consiste en la compra o venta de títulos según se requiera cubrir defectos o controlar excesos de liquidez circulante.

$\mathrm{Su}$ parecido con las OMA es enorme. No obstante, la diferencia radica en su carácter transitorio para solventar dificultades coyunturales del mercado con visos de temporalidad. De esa forma los desajustes temporales de liquidez se manejan mediante repos y las OMA se utilizan para el control de los agregados monetarios a largo plazo.

En general las OMA se constituyen en el mecanismo de control monetario más eficiente y moldeable de acuerdo con las condiciones del mercado:

El hecho de que las operaciones de mercado abierto funcionen siempre a iniciativa del Banco Central (a diferencia de las de redescuento) y de que sus efectos operen monetariamente a través de la base y no del multiplicador (a diferencia de las variaciones del encaje minimo), le otorgan al instrumento mayor precisión y lo hacen predecible en sus efectos. Aparte de esto, estas operaciones pueden hacerse en montos grandes o pequenos, en forma continua en el tiempo y son fácilmente reversibles, por lo que el instrumento posee una enorme flexibilidad. Además por tratarse de operaciones en que el público participa en forma totalmente voluntaria, esa participación no provoca efectos secundarios negativos, el instrumento es siempre aceptado con buen grado (Bianchi, 1994, p. 77).

Por ser un mecanismo basado en el mercado, genera cambios más rápidos, extensos y precisos en la tasa de interés y en el agregado monetario, sin causar en el sistema distorsiones artificiales o sesgos en contra de determinados sectores.

Enunciemos ahora algunas funciones básicas de las OMA en el mercado monetario como herramienta de control y sus efectos directos sobre algunos indicadores y agregados. 


\section{Funciones de las OMA}

Habida cuenta de las diversas discusiones doctrinales, podemos avizorar el planteamiento de unas funciones específicas endilgadas a las OMA y que sintetizamos de la siguiente manera:

- Control monetario ejercido por el Banco Central, contrarrestando cualquier tendencia inflacionaria o deflacionaria en el medio circulante, que afecte los programas de crecimiento y producción en el esquema económico, mediante el uso de operaciones de mercado abierto.

- Fomentar la inversión de capital privado en dichos títulos y de contera el ahorro de recursos.

- Aumentar la liquidez o equilibrar los precios de los documentos seleccionados para tales operaciones, de conformidad con las leyes de la oferta y la demanda.

- Contribución al logro de objetivos de política monetaria a nivel nacional, en desarrollo del principio de coordinación.

\subsection{Efecto de las OMA sobre el mercado \\ 4.1.1 Tasas de interés}

El aumento en la demanda de títulos o bonos eleva el precio de esos documentos y colateralmente ocasiona la disminución en la tasa de interés en los mismos, ocasionando un efecto inverso entre precio del bono y el tipo de interés. La caída en los intereses de estos títulos, redunda en la tasa aplicable a otros documentos, afectando la economía en su conjunto. A contrario sensu la venta de los títulos aumenta la tasa de interés. No obstante se advierte: Sin embargo una condición imprescindible para llevar a cabo dicho control, es el volumen de los titulos que esté en capacidad de absorber el público interesado, ya que solo una cantidad de papeles podrá implicar cambios de alguna magnitud sobre las tasas de interés (Síntesis Económica, 1976, p. 9).

En la búsqueda del objetivo regulatorio, la autoridad monetaria tiene la potestad de modificar la tasa de interés de los títulos y lograr así las metas de contracción o expansión que demande la necesidad de equilibrio.

\subsubsection{Base monetaria}

Las OMA tienen un efecto directo sobre la emisión de dinero. La base resulta de sustraer los activos del Banco de la República y a la moneda de la tesorería los pasivos no monetarios; con esa variable y aplicando el multiplicador se establecen los medios de pago existentes. Así las cosas, las OMA tienden a afectar directamente el dinero en circulación contrayendo o expandiendo la base en comento.

\subsubsection{Intermediarios financieros}

Por tratarse de decisiones voluntarias, la afectación a los distintos sectores es más homogénea que los instrumentos impositivos, produciendo los mismos impactos sobre el mercado financiero en su conjunto. De otra parte es más eficiente en tanto los costos son asumidos por quienes voluntariamente deciden comprar o vender los títulos emitidos para tal fin.

\subsubsection{Riqueza neta}

Un aumento en la oferta de dinero incrementa el nivel de precios, disminuyendo el valor de la base monetaria y consecuencialmente se reduce la riqueza real. Si consideramos dentro de este 
último concepto la deuda del Gobierno, siendo en este aspecto similares los efectos entre las OMA y el encaje bancario, el impacto sobre la demanda agregada es evidente.

En virtud de la liquidez secundaria que brindan y su contribución a diversificar formas de captación, esta clase de operaciones ayudan sensiblemente al desenvolvimiento del mercado: Los títulos de las operaciones de mercado abierto, captan recursos de corto plazo que de otra manera podrian acelerar el ritmo del gasto privado, presionando la estabilidad de precios, al tiempo que contribuyen a la generación de ahorro interno necesario en un proceso de acumulación de reservas internacionales (Banco de la República, 1986, p. 16).

La flexibilidad de las OMA permite modificar, cuando sea necesario, las condiciones de los títulos, para controlar rápidamente cambios estacionales en la liquidez a la par que se diversifican las opciones de mercado.

Señaladas las funciones y efectos, indiquemos ahora las condiciones materiales necesarias para la óptima utilización del mecanismo bajo estudio.

\section{Condiciones para la viabilidad de las OMA}

Para lograr la eficacia de un instrumento de control monetario como las operaciones de mercado abierto, se requiere como condición previa la estabilización de la moneda, además de contar con un mercado de dinero abundante. Siguiendo ese derrotero de interpretación, podemos aseverar que las siguientes son las condiciones mínimas para la implantación exitosa de las OMA en un mercado monetario.

\subsection{Condiciones macroeconómicas}

Las tasas de interés de los valores negociables deben ser determinadas por las fuerzas del mercado y utilizar para su colocación mecanismos como la subasta pública. Al tratar de impulsar tasas artificiales con el fin de contener el déficit fiscal causado por el servicio de la deuda interna mediante OMA, desnaturalizan su razón de ser como instrumentos libremente negociables, desprovistos de las rigideces propias de otros mecanismos, perdiendo de esa forma su virtuosidad dúctil y moldeable de acuerdo a las condiciones de mercado.

La estabilización macroeconómica presupone la concurrencia de varios factores, entre ellos el diseño de políticas fiscales austeras inmersas en un proceso más amplio de liberalización y reforma financiera, bajo la supervisión y control de los entes estatales especializados para tal efecto, limitando la excesiva extensión de créditos con bases inapropiadas de intermediarios y su concentración riesgosa. Dicha estabilización facilita también la transición de las inversiones a largo plazo con tasa fija dentro de un esquema de liberación de tasas de interés y de niveles de crédito. Sobre el particular se comenta:

La liberación financiera debe ir aparejada a las OMA, debido a que, al eliminar los controles de tasas de interés y de crédito, el Banco Central dependerá de dichas operaciones para manejar la liquidez del sistema bancario. Así, la liberalización financiera favorece una politica monetaria eficaz, lo cual a su vez apoya los esfuerzos de estabilización propiciando la profundización financiera, la cual promueve la 
eficacia de las OMA y así sucesivamente, en un circulo virtuoso (Bianchi et. al., p. 110).

Reiteramos que el proceso de liberalización debe estar acompañado de un control riguroso que facilite la concreción de las medidas de transición, sin incurrir en flexibilizaciones que tiendan a colapsar el sistema a través de la materialización del riesgo sistémico.

\subsection{Capacidad y autoridad del Banco Central}

Se reitera en este punto que el otorgamiento directo de créditos del Banco Central al Gobierno tiene efectos inflacionarios, de allí que no se debe constreñir a dicho ente para acceder a empréstitos; así lo entendió la Constituyente al restringir ese tipo de transacciones en su artículo $373^{5}$. El debate en el seno de la Constituyente fue entonces cómo evitar que el Banco Central se convierta en acreedor del Gobierno, limitando sus funciones a ser un agente fiscal e intermediario de inversiones: El pais requiere, entonces, que la política monetaria se dirija de acuerdo con criterios técnicos, aislada de ocasionales intereses coyunturales, para que ella colabore al desarrollo nacional y, particularmente, al mantenimiento de la capacidad adquisitiva del ingreso de los colombianos (Steiner, 1995, p. 249).

A su vez, el manejo de OMA requiere de personal calificado en la materia

(...) Las operaciones de financiamiento a favor del Estado requerirán la aprobación unánime de la junta directiva, a menos que se trate de operaciones de mercado abierto. El legislador, en ningún caso, podrá ordenar cupos de crédito a favor del Estado o de los particulares. con capacidad para tomar decisiones oportunas de cuándo intervenir y cuándo abstenerse de hacerlo de acuerdo con las señales del mercado. La información oportuna y precisa debe fluir entre los diferentes partícipes en el mercado de activos financieros y la política monetaria debe ejecutarse en coordinación con la política fiscal a cargo del Gobierno Nacional, para el cumplimiento de los programas macroeconómicos.

Lo anterior no implica dependencia sino coordinación. Es axial que el Banco Central cuente con un nivel de autonomía apropiado que le permita tomar determinaciones con gran flexibilidad.

Como se resalta por la doctrina en relación con el relevante papel del emisor en el control monetario:

El Banco de la República, rediseñado por la Constitución de 1991, logró mantener una mayor disciplina monetaria; esta a su vez, indujo una reducción de la inflación apreciable pero no ha logrado alcanzar los niveles internacionales. Se obtuvieron al mismo tiempo, una profundización considerable del mercado de capital, sobre todo en la emisión de titulos del Gobierno, y la ampliación del crédito privado (Kalmanovitz et. lit., 2010, p. 176).

Desde esa perspectiva, la autonomía del emisor ha sido un factor de vital importancia en el control de la base monetaria como elemento estabilizador de precios. Sin embargo, aún falta mucho trecho por recorrer en lo referente al logro de estándares internacionales sostenibles en el mediano y largo plazo. 


\subsection{Desarrollo del \\ mercado de dinero}

Los valores que se ofrezcan en subastas públicas de operaciones de mercado abierto deben contar con tasas de interés atractivas para los potenciales adquirientes, actitud que, contrario a los estándares prediseñados, coadyuva a la profundización financiera, haciendo más transparente su manejo.

Los documentos negociados deben gozar de un amplio respaldo en el mercado secundario, es decir deben ser líquidos, con amplios plazos, estabilidad de tasas de interés nominales y reales. Se debe evitar el abuso de la posición dominante evitando prácticas monopolísticas, ampliando la esfera de destinatarios de las OMA de manera considerable, así como un control estricto sobre los agentes que tienden a especular con la liquidez a tasas de interés excesivas.

En la actualidad es pertinente robustecer la supervisión estatal sobre los agentes colocadores de OMA, habida consideración de la inminente entrada en funcionamiento de la fusión de la plataforma de negociación transaccional de la Bolsa de Valores de Colombia con la de Lima y Santiago de Chile. Lo anterior, en aras de prevenir la configuración de conductas contrarias al mercado que militan en contra de la necesaria transparencia e integridad del mismo, lo cual le resta credibilidad e impide su profundización para atraer nuevos inversionistas y emisores.

Revisemos ahora el marco normativo que regula la utilización de las OMA y su desarrollo jurisprudencial que disciplina en la práctica el accionar de este tipo de herramientas.

\section{Régimen constitucional y legal de las OMA}

La Constitución Política en sus arts. 371 y siguientes confiere al Banco de la República la función de regular la moneda y le otorga a su Junta Directiva la facultad de ser la autoridad monetaria, cambiaria y crediticia, conforme a las funciones que le asigne la ley.

Por mandato constitucional, el Estado, por medio del Banco de la República, velará por el mantenimiento del poder adquisitivo de la moneda y se proscribe la posibilidad de realizar operaciones de financiamiento a favor del Estado, para lo cual se requiere decisión unánime de los miembros de la Junta Directiva, a menos de que se trate de operaciones de mercado abierto, en las cuales no se financia directamente al Gobierno, sino que se negocian documentos en el mercado financiero para lograr objetivos de estabilidad en la base monetaria.

Sobre la función reguladora de la moneda y la independencia respecto al ejecutivo, se argumentaba: De esta forma, la independencia de la Banca Central y la especialización de su objetivo para lograr la estabilidad de precios y la solidez del sistema financiero constituyen un elemento positivo en la creación de un ambiente de credibilidad en el manejo económico (Banco de la República, 1994, p. 19). La aspiración del constituyente por modernizar la estructura de la Banca Central y dotarla de las herramientas necesarias para el logro de sus objetivos, debe entenderse en coordinación con una política fiscal austera que equilibre la ecuación macroeconómica fundamental:

Es comúnmente aceptado que a largo plazo la política monetaria 
puede lograr únicamente estabilidad de precios. La asignación al Banco Central de objetivos adicionales, a corto plazo, como la política de estabilización, requiere "contratos" más complicados en los que el alcance de las tentaciones inflacionarias subóptimas es mayor. Dejarle la estabilidad de la economía a la politica fiscal y exigirle al $B C$ concentrarse en la estabilidad de precios, reduce este riesgo (Cukierman, 1997, p. 125).

La existencia de relaciones compensatorias entre ambas herramientas, hace posible que una utilización coordinada y planificada arroje como resultado un nivel óptimo de estabilización económica.

A pesar de las ventajas expuestas en el sentido de enfocar una política monetaria utilizando OMA como elementos flexibles y útiles en relación con el mercado, existen voces disidentes que propugnan porque el Banco no emita dichos documentos por los altos costos que en su balance refleja tal situación: Ahora bien, como las operaciones de mercado abierto constituyen pasivos del Banco, al mirar el balance por el lado activo resulta perfectamente obvio que ése es el costo que se está pagando por tener reservas internacionales superiores a las que requiere la economía. En el futuro, como se anotó, el emisor de documentos tendrá que ser el gobierno y no el Banco (Cuéllar, 1996, p. 298). Lo que se propone es que el costo de la política monetaria afecte directamente el presupuesto nacional y como rezago de un año, de tal suerte que se reduzca el riesgo de expandir el medio circulante por la utilización de recursos fiscales derivados de la misma inflación.

En desarrollo del mandato constitucional se expidió la ley 31 de 1992, en la cual se consagran las normas a que deberá sujetarse el Banco del República en el ejercicio de sus funciones. Dentro de la ponencia para primer debate se sustentaba la necesidad de afianzar la independencia y autonomía en las materias propias de su competencia, dispensadas expresamente por la Constitución para el logro de objetivos propuestos, teniendo la potestad de tomar las determinaciones que juzgue convenientes. Para tal fin, se expresó en Ponencia para Primer Debate en el Senado del proyecto de ley $93 \mathrm{de}$ 1992:

De otra parte y sólo con el único propósito de regular la moneda y para atender necesidades de contracción y ampliación de la base monetaria, según sea necesario, la Constitución facultó al Banco para realizar operaciones de mercado abierto, emitiendo y comprando sus propios titulos de deuda pública del gobierno en el mercado secundario (p.5).

De lo anterior se colige que tanto desde la perspectiva constitucional como legal, las OMA se constituyen en el mecanismo de control monetario por excelencia, circunstancia que debe enmarcarse dentro del contexto de un emisor que está facultado para motu propio diseñar y regular la política monetaria, en coordinación con el marco macroeconómico general, guardando siempre el objetivo fundamental de mantener la estabilidad de la moneda y propender por la preservación de su poder adquisitivo.

\subsection{Jurisprudencia constitucional}

La precitada ley 31 de 1992 consagró en su art. 16 literal b), en torno a las 
funciones de la Junta Directiva como autoridad monetaria, cambiaria y crediticia la siguiente:

\section{Ley 31 de 1992.}

\section{ART. 16-Atribuciones:}

b. Disponer la realización de operaciones de mercado abierto con sus propios títulos, con títulos de deuda pública o con los que autorice la junta directiva, en estos casos en moneda legal o extranjera, determinar lo intermediarios para estas operaciones y los requisitos que deberán cumplir estos.- En desarrollo de esa facultad podrá disponer la realización de operaciones reportos (repos) para regular la liquidez de la economía.

De allí se deriva la autorización de orden legal para la realización de OMA como instrumentos de control y regulación sobre el medio circulante. En relación con estas potestades la Corte Constitucional se pronunció en los siguientes términos:

La norma legal atribuyó a la Junta Directiva del Banco, entre otras, las atribuciones de fijar y reglamentar el encaje de las distintas categorias de establecimientos de crédito y, en general, de todas las entidades que reciban depósitos a la vista a término de ahorro, señalar o no su remuneración y establecer las sanciones por infracción a las normas sobre esta materia, disponer la realización de operaciones de mercado abierto, determinar los intermediarios para las mismas y los requisitos que deberán cumplir, señalar mediante norma de carácter general las condiciones financieras a las cuales deberán sujetarse las entidades públicas autorizadas por la ley para adquirir o colocar titulos con el fin de asegurar que estas operaciones se efectúen en condiciones de mercado; señalar en situaciones excepcionales límites de crecimiento a las operaciones de cartera y a las demás operaciones activas que realicen los establecimientos de crédito (Corte Constitucional. Sala Plena. Sentencia: C - 489 del 3 de noviembre de 1994. M.P. Dr. José Gregorio Hernández Galindo, p. 10).

En relación con las leyes que regulan el funcionamiento del Banco y la competencia del Congreso para dictar normas de carácter general, sin inmiscuirse en la competencia Constitucional del emisor, la Corporación señaló: Debe advertirse que las leyes mediante las cuales se establecen las reglas referentes a las funciones del Banco de la República y de su Junta Directiva, no tienen una categoría especial dentro de la estructura del orden jurídico colombiano, pues la Constitución no las ha dotado de un nivel jerárquico superior ni ha exigido determinados requisitos de indole formal para su aprobación como si acontece con las leyes estatutarias y las orgánicas (Corte Constitucional, Et. lit. p. 12).

Por tanto, la interpretación que se prohíja en este fallo, no consiste en sostener que una vez expedidas tales leyes por el Congreso quede afectada su facultad legislativa sobre la materia; ésta se mantiene en toda su plenitud y por tanto normas como las contenidas en la ley 31 de 1992 pueden ser modificadas, adicionadas $\mathrm{y}$ 
sustituidas o derogadas cuando en ejercicio de sus competencias el Congreso lo juzgue pertinente.

Lo que le está vedado al parlamento, en cuanto con ello lesiona su autonomía funcional del Banco de la República y quebranta la Constitución, es sustituir a dicho ente en el ejercicio concreto de sus atribuciones como autoridad monetaria, cambiaria y crediticia o dictar disposiciones específicamente destinadas a regular casos concretos, ya que al actuar de esa manera el legislador abandona su función propia, la de expedir normas generales y abstractas, a las cuales debe sujetarse el Banco, y asume la de un órgano distinto al cual la Carta Política ha querido confiar la decisión en las aludidas materias de dirección económica ${ }^{6}$.

De esta manera se garantiza la autonomía de la Banca Central en el logro de sus objetivos, sin desconocer el engranaje estatal al que pertenece y que le obliga a coordinar acciones con el marco macroeconómico general, logrando un punto intermedio saludable para el ejercicio de su competencia.

Sobre el particular, es pertinente resaltar que la reciente reforma financiera eliminó la restricción que establecía el artículo 53 de la ley 31 de 1992, abriéndose de esa forma la posibilidad de que se realicen ese tipo de transacciones con títulos emitidos por el mismo Banco de la República y no solamente con Títulos de Deuda Pública como venía ocurriendo desde el año 1999.

\footnotetext{
Sobre el mismo tema consultar: Sentencia C-021 del 27 de enero de 1994. M.P. Antonio Barrera Carbonell. Sentencia C- 050 del 10 de febrero de 1994. M.P. Hernando Herrera Vergara y Sentencia C - 521 de noviembre de 1994. M.P. Dr. Jorge Arango Mejía.
}

Ahora bien, tras el recuento conceptual y doctrinal efectuado, adentrémonos en la práctica en la funcionalidad operativa del instrumento bajo estudio:

\section{Agentes colocadores de OMA}

A raíz de la expedición de la Resolución 50 de 1990, el Banco de la República puede realizar operaciones de mercado abierto a través de la colocación de títulos por la vía de las ofertas, remates y subastas en el sistema financiero, con los comisionistas de bolsa y las demás personas que se señalen conforme a una reglamentación especial.

Para expedir la autorización de colocación se evalúa la capacidad técnica y administrativa, la información financiera, su experiencia en el ramo, etc. Actualmente pueden ser colocadores de OMA las firmas de comisionistas de bolsa y las sociedades fiduciarias a nombre de terceros y a nombre propio: los establecimientos bancarios, las corporaciones financieras, las compañías de financiamiento, las sociedades administradoras de fondos de pensiones y cesantías, así como la Dirección General de Crédito Público y del Tesoro Nacional del Ministerio de Hacienda y Crédito Público.

Los criterios que se han tenido en cuenta para la selección de los agentes colocadores parten de un enfoque maximalista, en el que todos los agentes, cumpliendo con unos requisitos mínimos de talante financiero, podrán convertirse en agente colocador, propiciando una igualdad de condiciones y disponiendo de un grado de información sobre agentes con disponibilidad de recursos.

Otra visión es el enfoque minimalista, según el cual el Banco debe elegir 
solamente pocos agentes colocadores que reúnan una serie de requerimientos más restrictivos. La ventaja de este enfoque radica en tratar con menos agentes y por ende se logra mayor eficiencia y compromiso con la captación de recursos respecto de sus clientes o, en última instancia, las mismas entidades asumirían el costo de adquisición de los respectivos valores.

Lo ideal es desembocar en un enfoque intermedio (Rodríguez y Pinedo, 1994, p. 4) que garantice el acceso en igualdad de condiciones, pero que establezca períodos de prueba para evaluar el rendimiento $y$, dependiendo del mismo, dar continuidad o terminar con la autorización expedida, lo cual constrińe a los participantes como agentes a desempeñar un papel activo y lograr resultados que respalden su gestión. Las transacciones realizadas por este sistema compensan el costo de oportunidad del dinero, gracias a su rentabilidad, ante una situación de altas tasas de interés sin que los intermediarios se afecten en su liquidez.

Lo anterior se robustece ante el positivo comportamiento de la última déca$\mathrm{da}$, especialmente para el sector financiero, el cual cumple un papel vital en el coadyuvar en el control monetario. Para ese período se aseveraba: El período 20002007 ha sido de recuperación económica, así como la tendencia del sector bancario a realizar fusiones y adquisiciones; asi se observa que el tamaño promedio de un banco como porcentaje de los activos de la entidades de crédito para el 2007 es de $79 \%$ a diferencia del 2000 en el que fue de 62\% (Sarmiento y Cristancho, 2009, p. 36).

En la actual coyuntura, signada por la recuperación de las economías afectadas por la crisis y ante las incesantes amenazas de ingresos masivos de divisas por las exportaciones de commodities, cobra especial relevancia la utilización del mecanismo descrito como herramienta eficaz para controlar el exceso de circulante que afecte la estabilidad de la base monetaria, máxime en un contexto en el cual se avizora como un sector que impulse el desarrollo económico en el mediano plazo: el renglón minero energético. Esto implica, necesariamente, ingreso masivo de recursos y la necesidad de controlar su paulatina absorción por la economía sin generar traumatismos tales como la enfermedad holandesa, frente a los cuales las OMA se erigen en un plausible mecanismo de estabilización monetaria.

\section{Conclusiones}

Las OMA constituyen un instrumento de política monetaria que actúa sobre la liquidez global del sistema económico, es decir, afectan la emisión primaria de dinero. Fundamentalmente consisten en la compra y venta de títulos respectivos de deuda pública por parte de las autoridades monetarias o del Banco Central, con el objetivo específico de ejercer control sobre los medios de pago y regular la base monetaria.

La realización de este tipo de operaciones con valores transables en los mercados organizados, implica la captación de un determinado número de recursos compitiendo libremente en el mercado. Dichos recursos son congelados en el Banco de la República, de tal forma que la venta de títulos implica la contracción de la oferta monetaria y, la posterior recompra, representa una expansión de los medios de pago; de esa forma se regula la liquidez global de la economía.

Las operaciones de mercado abierto son la herramienta flexible, eficiente y 
eficaz para evitar el desbordamiento de los medios de pago, toda vez que la inversión en las mismas es voluntaria y se hace de conformidad con las reglas del mercado. Esto es, con tasas de interés competitivas, logrando un efecto directo sobre la base monetaria, las tasas de interés de corto plazo y a través del multiplicador monetario, sobre agregados de dinero más amplios y tasas de interés de mayor plazo. Su uso no genera externalidades negativas por la forma voluntaria de participación dirigido a todo el público en general y no sólo a las instituciones financieras, contrario a lo que ocurre con otros instrumentos de control monetario como el encaje marginal, que son impuestos por la Banca Central, originando artificialidades en el mercado que terminan causando síndromes recesivos.

Las ventajas comparativas de las OMA respecto al encaje, son evidentes por cuanto éste último congela la expansión secundaria sin alternativas de acción, reflejándose en la pérdida dentro del total de operaciones del sistema financiero, entrabando el dinamismo económico y de contera frenando el desarrollo productivo por las restricciones de crédito. En ese aspecto las OMA son más consecuentes con la realidad y necesidades del mercado, tomando en cuenta sus potencialidades como instrumento desprovisto de rigideces impositivas.

La autoridad monetaria puede incidir decisivamente sobre los medios de pago en circulación mediante las OMA que son susceptibles de modificación en su tasa de interés, plazo, cantidad y valor de los documentos negociables. Esos cambios pueden implantarse de manera inmediata respondiendo a coyunturas y a la flexibilidad y dinamismo propio del mercado de capitales, por virtud de la moldeabilidad en su manejo. La acción del mecanismo recae sobre el conjunto del mercado financiero, afectando homogéneamente a todos los intermediarios que lo componen.

No obstante las ventajas enunciadas, el éxito de las OMA depende de un grado apropiado en el desarrollo del mercado de capitales con tradición de ahorro privado. En Colombia la concentración de ingreso no permite una generación significativa de ahorro, pues los índices inflacionistas desvían recursos hacía actividades especulativas sin acrecentar bienes de capital.

Se hace necesario crear un núcleo de negocios asumido por los volúmenes crecientes de dichos títulos que redunden en el dinamismo del mercado secundario. Por las razones expuestas no se puede utilizar a las OMA como el único mecanismo de control monetario y es preciso apelar al encaje, combinando ambas figuras para lograr la estabilidad del sistema.

En el panorama colombiano, debido a la estrechez y escaso desarrollo del mercado de capitales, se dificulta el aprovechamiento del instrumento en términos de eficiencia, toda vez que se hace imperiosa la existencia de un nivel de ingresos altos para que el público ejercite su ahorro a través de estos títulos. Desafortunadamente el sistema colombiano no se caracteriza por los hábitos de ahorro e inversión en razón a la escasa redistribución de la riqueza (Revista Dinero, 2010, p. 10).

No obstante lo anterior, la política macroeconómica ha sido relativamente estable en la última década, circunstancia que ha sido reconocida por instancias internacionales. A título ilustrativo funcionarios del Fondo Monetario Internacional 
frente al manejo de la reciente crisis global indicaron: Los Directores Ejecutivos elogiaron a las autoridades colombianas por la aplicación de politicas macroeconómicas adecuadas y por la amplia gama de reformas estructurales que han contribuido a acelerar el crecimiento y reducir las vulnerabilidades, señaló el informe (Revista Dinero, 2009).

Ergo, las OMA según las consideraciones efectuadas, son el instrumento de control monetario más efectivo y menos propenso a generar distorsiones en el mercado financiero siempre y cuando se cuente con las condiciones materiales apropiadas para su viabilidad. Un ambiente de estabilidad fiscal, confianza en la inversión y crecimiento con equidad, podrán proporcionar la base adecuada para la expansión monetaria en el largo plazo, de acuerdo a los requisitos de liquidez del crecimiento económico, colateralmente su influencia en el nivel y estructura de la tasa de interés, de acuerdo con los objetivos y requerimientos financieros generales.

Una correcta asignación entre instrumentos y unas variables - objetivo, claramente definidas, pueden conseguir una programación de la política monetaria, acorde con los requerimientos de crecimiento económico del país.

En el devenir de las instituciones estudiadas, es preciso que el derecho acompañe los cambios que se requieren para la efectividad de los instrumentos de política monetaria, haciendo moldeables sus instituciones. Lejos de obstaculizar el desarrollo económico, manteniendo el statu quo, el avance y complejidad de la estructura exige el diseño de nuevas instituciones, figuras, visiones, interpretaciones y sistematizaciones, con el fin de hacer frente a un periodo caracterizado por panoramas inciertos: Fracasados los modelos extremos o puros, es tarea de la normatividad jurídica propugnar por aquellos que preserven los valores trascendentales. No otra, en sintesis, es la función del derecho, y no solo del derecho económico (Vásquez, 1998, p. 30).

Las normas del derecho económico no pueden interpretarse y aplicarse inflexiblemente, pues el sistema de mercado libre se aleja con frecuencia de ser un modelo perfecto y armónico. Las normas deben interpretarse con un sentido finalista en relación con el objetivo que persiguen. La intención del legislador, que erróneamente se confunde con el espíritu de la ley, no es aplicable a la interpretación de esta normatividad, sino más bien la interpretación teleológica pues la norma responde a una realidad económica como expresión de una realidad auténtica, encaminadas a producir efectos en el accionar social.

Frente a esa materia en particular, en el curso del presente trabajo se evidenciaron las ventajas comparativas de este mecanismo de mercado para el control eficiente de la base monetaria frente a otras herramientas con similar finalidad, lo cual haría necesario contar con un marco normativo más prolífico del existente, caracterizado por su claridad y adaptabilidad a las circunstancias inopinadas de mercado.

Igualmente, sería procedente estudiar por parte de la Junta Directiva del Banco de la República, la posibilidad de autorizar la emisión de títulos propios del Banco para la celebración de este tipo de operaciones, alternativa viable a raíz de la derogatoria de la restricción normativa que en ese sentido contenía la ley 31 de 1992 por la última reforma financiera (ley 1328 de 2009). Dicha circunstancia favorecería una separación entre 
el espacio fiscal y el eminentemente monetario en la realización de OMA, por cuanto no se utilizarían títulos de deuda pública exclusivamente para instrumentalizar este tipo de transacciones, sino otro tipo de activos diferentes, lo cual tendría efectos benéficos sobre el perfil del endeudamiento público.

Como corolario de lo anterior tenemos que, a pesar de las ventajas reseñadas en el decurso del presente trabajo, es menester profundizar la utilización del emisor y establecer un marco normativo actualizado y flexible que se proyecte a nuevas realidades, tales como la transnacionalización del mercado de capitales por la fusión de escenarios bursátiles con Perú y Chile, y la profundización del mercado de valores ante la entrada en funcionamiento de los multifondos en pensiones obligatorias. Panorama que permite ensanchar la variedad de los papeles con los cuales potencialmente se podrían efectuar las OMA por parte del Banco Central ya sea con títulos propios o con otros valores transables en el mercado.

El Gobierno Nacional ha proyectado como uno de los motores que impulsen la economía en el mediano plazo el sector minero energético, lo cual implica el ingreso masivo de divisas por concepto de las exportaciones y de contera una seria amenaza a la estabilidad monetaria. Frente a esta circunstancia las OMA pueden ayudar mucho como factor estabilizador que coadyuve al desarrollo y crecimiento económico sostenible.

\section{Referencias}

I. Aguirre, E. et al. (1997) La banca central en América Latina. Bogotá: Tercer Mundo Editores, Banco de la República.

2. Banco de la República. (1994). Algunas consideraciones sobre el manejo de las $O M A$. Documento. Bogotá: Unidad Técnica.

3. Banco de la República. (1994). Consideraciones sobre el manejo de la liquidez en el corto plazo. Bogotá: Subgerencia Monetaria de Reservas, Unidad Técnica.

4. Banco de la República. (2002) Introducción al análisis económico, el caso colombiano. Bogotá: Siglo del Hombre Editores.

5. Banco de la República. (1994). La banca central en Colombia: normas básicas. Bogotá: Colección Bibliográfica.

6. Beltrán González, X. (1990). Las OMA: aún sin explotar. En: Síntesis Económica, Bogotá: Junio 4 de 1990, No. 718, p. $20-21$.

7. Bianchi, A. et al. (1994). Reformas y reestructuración de los sistemas financieros en los paises de América Latina. México: Centro de Estudios monetarios Latinoamericanos.

8. Botero Arboleda, C. H. (1987). Las operaciones de mercado abierto frente a la politica de encaje, como instrumento de control monetario. Bogotá: Tesis: Universidad de los Andes, Facultad de Economía.

9. Colombia preparada para la crisis 27. En: http://www.dinero.com/economia/ crecimiento/colombia-preparada-paracrisis-fmi_56426.aspx.

Io. Corfivalle. (2006). Consultorio Económico Financiero. Cali: Corporación Financiera del Valle. 
I I . Corte Constitucional. Sala Plena. Sentencia: C-489 del 3 de noviembre de 1994. M.P. Dr. José Gregorio Hernández Galindo.

I 2. Corte Constitucional. Sala Plena. Sentencia C-680 de 2009, Mag. Ponente: Dr. Nilson Pinilla.

I3. Cuéllar de Martínez, M. M. (1996). Competencias Cambiarias, Monetarias y Crediticias del Banco de la República. En: Constitución Económica Colombiana. Bogotá, Biblioteca Millenio, El Navegante Editores, p. 293 - 298.

I 4. Dornbusch, R., Fischer, S. A. y Startz, R. (2004). Macroeconomía. Madrid: Mc Graw Hill.

I 5. Giraldo Salazar, O. (1984). Las operaciones de mercado abierto y su incidencia en el Mercado Bursátil durante 19761983. Bogotá: Pontificia Universidad Javeriana, Facultad de Ciencias Económicas y Administrativas.

I6.Gondour, M. (2008). Constitución Fiscal y equilibrio de las finanzas públicas. Efectos de la Constitución de 1991 sobre la economía política del financiamiento del gasto público en Colombia. Revista Colombia Internacional. Facultad de Ciencias Sociales, Universidad de los Andes.

I7. Hoyos Arango, S. (1974). Operaciones de mercado abierto. Revista de la Contraloría General de la República, 103, 6-7.

I 8.Instrumentos de control monetario. (1986). Revista No. 707, p. 3-16, Bogotá: Banco de la República.

19. Kalmanovitz, S. (2010). Nueva historia económica de Colombia. Bogotá: Fundación Universitaria Jorge Tadeo Lozano.

20.La Banca Central en Colombia: normas básicas. (1994). Bogotá: Colección Bibliográfica. Banco de la República.
2 I.Ley Número 31 del 29 de diciembre de 1992.

22.Ley Número 964 del 8 de julio de 2005.

23. Narváez García, J. I. (1993). Soportes Constitucionales del Derecho Económico. En: Foro del Jurista, Medellín: Volumen 6, No. 14. p. 61-65.

24. Pinzón de Velazco, I. y Name de Farfán, B. (1983). Operaciones de Mercado Abierto: Herramienta Estabilizadora. Bogotá: Tesis: Pontificia Universidad Javeriana, Facultad de Economía.

25. Reich, N. (1985). Mercado y Derecho. Barcelona: Editorial Ariel Derecho.

26. Restrepo Salazar, J. C. (1985). Finanzas y Financistas. Bucaramanga: Editorial SIC.

27.Restrepo Salazar, J. C. (1995). Hacienda Pública. Bogotá: Universidad Externado de Colombia.

28. Restrepo Salazar, J. C. Y Núñez, A. J. (2009). Diálogos sobre las crisis financieras. Bogotá: Biblioteca Jurídica Dike.

29. Rodríguez López, C. A. y Pineda, F. (1998). Agentes Colocadores de OMAS. Bogotá: Documento Banco de la República.

30. Revista Dinero. (Octubre de 2010). Bogotá: Colombia en su cuarto de hora, p. 10 .

3I.Revista Dinero. (2009). Colombia preparada para la crisis. (2009). Bogotá: Enero 27. En: http://www.dinero.com/ economia/crecimiento/colombia-preparada-para-crisis-fmi_56426.aspx.

32.Las operaciones de mercado abierto: un eficaz instrumento de regulación monetaria. Revista sintesis económica. (1996). Bogotá: No. 11.

33. Sarmiento, J. A. y Cristancho, L. A. (2009). Evolución del sistema financiero Colombiano durante el periodo 1980-2007. Revista facultad de Cien- 
cias Ecónomicas, Volumen XVII Junio, Universidad Militar Nueva Granada.

34. Sierralta Rios, A. (1988). Introducción a la Juseconomía. Lima: Pontificia Universidad Católica del Perú, Fondo Editorial.

35.Steiner, R. (Compilador). (1995). La Autonomía del Banco de la República. Bogotá: Tercer Mundo Editores y Fedesarrollo.
36.Stiglitz, J. (1998). Macroeconomía. Barcelona: Ariel Economía.

37.Zuluaga, B. (2004). La Política monetaria: Teoría y caso Colombiano. Revista Apuntes de economía, No. 1. Marzo, Departamento de Economía, Universidad ICESI. 